\title{
ANAESTHESIA FOR CORRECTION OF OESOPHAGEAL STRICTURE IN A PATIENT WITH RECESSIVE EPIDERMOLYSIS BULLOSA DYSTROPHICA: CASE REPORT
}

\author{
B. Milne and J.K. Rosales
}

\begin{abstract}
Epidermolysis bullosa dystrophica is a rare hereditary disorder which presents significant anaesthetic problems. These include malnutrition and anaemia; electrolyte imbalance in severe cases; renal failure and amyloidosis in progressive disease; association with porphyria: a history of steroid therapy. Technical problems associated with the necessity to avoid trauma to the skin and mucous membranes include those related to management of the airway and avoidance of regional techniques, Venepuncture may be difficult and oesophageal stricture increases the risk of regurgitation and aspiration.

Anaesthetic management of a patient with epidermolysis bullosa dystrophica with oesophageal stricture presenting for colonic interposition is described and the problems associated with this disease are discussed.
\end{abstract}

EPIDERMOLYSIS BULLOSA DYSTROPHICA is a rare hereditary disorder (incidence estimated as 1 in 300,000 births) which presents significant anaesthetic problems. It is a member of the mechano-bullous diseases and the scarring polydysplastic type can be extremely disabling. Bullae are present at birth or appear in early infancy, developing spontaneously or at sites of trauma. The bullae are large and flaccid and may be haemorrhagic. These heal to leave atrophic scars or rarely may leave large raw surfaces cicatrizing to leave skin defects, especially on the external aspects of the limbs. Fingers and toes may be contracted by pseudo-webbing of scar tissue to form mitten-like syndactyly.

Mucous membranes are involved with bullae and ulcers, complicating feeding, and scarring may limit mobility of the tongue. The larynx may be affected and recurrent bullac of the oesophagus are relatively common. This may lead to oesophageal stenosis and difficulty in maintaining adequate nutrition. Abnormalities of the nails, conjunctiva and hair and malformed carious teeth also occur. Separation occurs between dermis and epidermis and the aetiology is uncertain.'

Most of the anaesthetic literature deals with oral, dental, and plastic reconstructive surgery. ${ }^{2-6}$ We present our experience with a case of colonic interposition for oesophageal stenosis.

B. Milne, M.D., Resident, Department of Anaesthesia, Montreal Children's Hospital \& Queens University, Kingston, Ont. J.K. Rosales, M.D., F.R.C.P.(C), Director, Department of Anaesthesia, Montreal Children's Hospital, Associate Professor, McGill University, Montreal, Quebec.

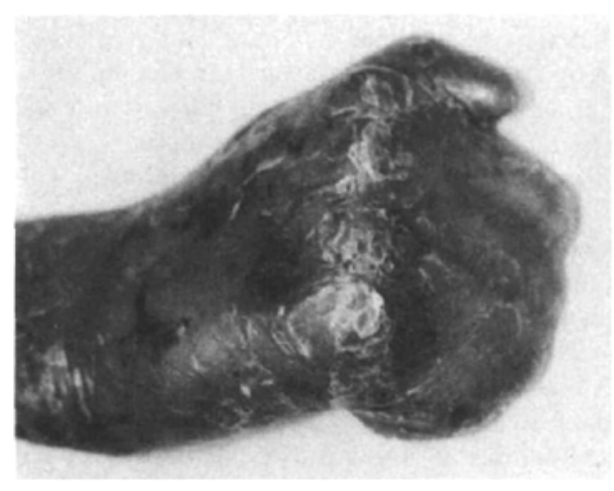

Figure 1 Syndactyly of fingers.

\section{Case History}

This ten-year-old girl was diagnosed as having epidermolysis bullosa dystrophica in infancy. There was no response to vitamin $A$ or zinc and there was no history of steroid therapy. She was admitted for investigation of vomiting and oesophageal stricture was discovered by barium swallow. Numerous bullae and open weeping lesions were present on the trunk, limbs and face, especially on the pressure points of the buttocks, elbows and knees. There was syndactyly of the fingers and toes with club shaped hands. She was unable to protrude her tongue due to scarring. Marked muscle wasting was evident and she had been below the third percentile for weight since the age of two. There was iron deficiency anaemia with a $\mathrm{Hgb}$ of $10.3 \mathrm{~g} / \mathrm{dl}$. Electrolytes, blood urea nitrogen and serum protein were within normal limits. 


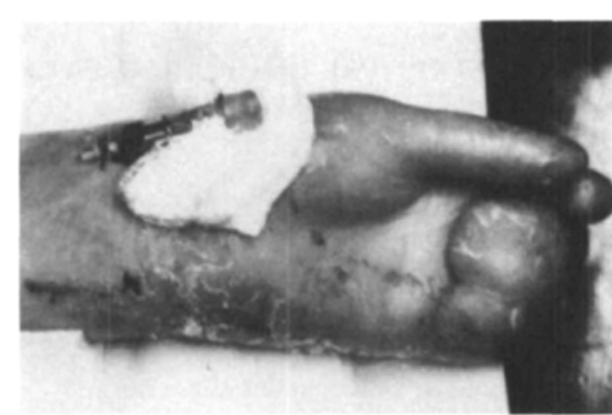

FICURE 2 Percutaneous arterial line sutured in place.

Previous anaesthetic experience consisted of three general anaesthetics with halothane, nitrous oxide, succinylcholine and orotracheal intubation; one was at the age of eight years for dental extraction and the others for oesophagoscopy and insertion of nasogastric feeding tubes during the two months prior to correction of the stricture. There were no complications.

Induction of anaesthesia was undertaken with halothane, oxygen and nitrous oxide using a lightly fitted mask. A central venous catheter was then placed percutaneously through the right antecubital fossa and sutured to the skin with nylon.

The elbow was wrapped loosely with flannel. After the administration of succinylcholine, tracheal intubation was carried out gently with a well-lubricated laryngoscope and a $6.5 \mathrm{~mm}$ cuffed orotracheal tube. The tube was secured with one inch flannel roll bandage. A left radial arterial line was inserted for continuous blood pressure monitoring using a 20-gauge needle and sutured in place with nylon.

A well lubricated oropharyngeal temperature probe was utilized. Eyes were lubricated and not taped. No electrocardiogram or blood pressure cuff was used. A heating blanket covered with several unwrinkled flannel blankets was used to cover the operating room table. Anaesthesia was maintained uneventfully with oxygen, droperidol, nitrous oxide, pancuronium and fentanyl. Blood transfusion was necessary.

The surgical procedure consisted of right colonic interposition through a mediastinal tunnel to bypass the stricture, incidental appendectomy and gastrostomy. The total time was seven hours. At the termination neostigmine and atropine was administered and the trachea was extubated to reduce the possibility of post-intubation difficulties. She was then transferred on her sheet to the hospital bed and taken to the intensive care unit for continuous arterial monitoring. The following day she was transferred to the ward. There were no complications.

\section{Discussion}

Epidermolysis bullosa dystrophica presents a number of problems for the anaesthetist. These include malnutrition and anaemia; electrolyte imbalance in severe cases; renal failure and amyloidosis in progressive disease; association with porphyria; a history of steroid therapy. Technical problems associated with the necessity to avoid trauma to the skin and mucous membranes include those related to management of the airway and avoidance of regional techniques. Venepuncture may be difficult and oesophageal stricture increases the risk of regurgitation and aspiration.

The need for the least possible degree of trauma has been well stressed in the past. The use of a face mask over soft cotton wadding lubricated with Gel and hydrocortisone ointment is advocated. Such a mask technique has been used with halothane, nitrous oxide and oxygen for emergency Caesarean section and this resulted in no facial bullae or airway obstruction. ${ }^{7} \mathrm{~A}$ well padded sphygmomanometer cuff, Doppler monitors or just palpation of force and rate of the carotid pulse have been used for assessing blood pressure. $7: 8$ We felt that continuous arterial monitoring, suturing the line in position, offered a good alternative for this seven-hour procedure and was beneficial for postoperative evaluation. There were no problems as a result of this. Electrocardiograph and precordial stethoscope were not used in order to avoid skin trauma from the use of self-adhering electrodes. Flannel bandage was useful in securing the tracheal tube and wrapping the site of insertion of the central venous pressure line. In a reported case large raw areas with serous discharge were left when the skin came right off upon removal of adhesive tape used to secure a tracheal ube, intravenous needle and precordial stethoscope ${ }^{13}$ It is surprising that there was no increase in bullae in our patient from pressure points during the seven-hour procedure. This is probably explained by the fact that it is the friction and not the pressure which is more important in the causation of these lesion."

Airway management can be difficult in these patients. Deformation and adhesion of the tongue may prevent maintenance of an oral airway. Profuse bleeding from buccal and soft palate areas may occur and sponges soaked in a solution 
of $1: 200,000$ epinephrine can be used for control of haemorrhage. ${ }^{10}$ Ketamine has been used successfully to avoid manipulation of the airway. ${ }^{1-14}$

Teeth are usually carious and malformed. In this case tracheal intubation was deemed essential and no complication such as postoperative stridor occurred due to placement of the tracheal tube or laryngoscopy. It is suggested the disease may effect primarily only squamous epithelium (mucosa of the tongue, lip, oropharynx, epiglottis) resulting in involvement of the upper but not the lower airway, since the laryngeal and tracheal lining is primarily pseudostratified columnar epithelium.?

Associated malnutrition, skeletal demineralization, and electrolyte abnormalities may present problems and total parenteral nutrition ${ }^{8}$ may be necessary postoperatively. Alteration in protein binding of drugs is a consideration. Many patients have had steroid therapy for epidermolysis bullosa and this should be taken into account as well as the necessity for baseline renal function due to the propensity for amyloidosis and renal failure ${ }^{3}$ There is a reported association with epidermolysis bullosa dystrophica and porphyria so the urine should be tested to rule out the presence of porphyria, or thiopentone should be avoided as in this case. ${ }^{9}$

Difficulties in venepuncture may present due to lack of visible veins beneath the parchment-like skin. Regional anaesthesia is relatively contraindicated because of the numerous skin lesions, many of them infected. Subcutaneous infiltration would certainly be detrimental.

\section{REFERENCES}

1. SNEDdon, I.B. Textbook of Dermatology. Eds Rook, A. et al. Second Ed., Vol. 2, pp. 1301-2, Oxford, Blackwell Scientific Publications (1972).
2. Marshall. B.E. A comment on epidermolysis bullosa and its anesthetic management for dental operations. Brit. J. Anaesth. 35: 724-727 (1963).

3. REDDY, A.R.R. \& WONG. D.H.W. Epidermolysis bullosa: a review of anaesthetic problems and case reports. Canad. Anaesth. Soc. J. 19: 536-548 (1972).

4. WILSON, F. Epidermolysis bullosa: a rare disease of anaesthetic interest. Brit. J. Anaesth. 3I: 26-31 (1959).

5. Young, D.A.\& Hardwick. D.B. Anaesthesia for epidermolysis bullosa dystrophica, Anaesthesia 23: 264-267 (1968).

6. Kubota, Y., Norton, M.L., Goldenberg, S. \& RoberTAZZI, R.W. Anesthetic management of patients with epidermolysis bullosa undergoing surgery. Anesth. Analg. 40: 244-249 (1961).

7. Berryhill, R.E., Benumof, J.L., Saidman, L.J.. Smith, P.C. \& Plumer, M.H. Anesthetic management of emergency cesarean section in a patient with epidermolysis bullosa dystrophica polydysplastica. Anesth. Analg, 57: 281-283 (1978).

8. Fonkalsrud, E.W. \& Ament, M.E. Surgical management of esophageal stricture due to dystrophicaepidermolysis bullosa. Journal of Pediatric Surgery 12: 221-226(1977).

9. ZaCKHEIM, H.S., RudzinSKi, D.J., KaTZ, J. \& SPADEMan, R.G. Anesthesia and uncommon diseases: physiologic and clinical correlations. Eds. Katz, J. and Kadis, L. B. Toronto, W.B. Saunders Co.pp. 446(1973)

10. Pratilas, V., \& Biezunski, A. Epidermolysis bullosa manifested and treated during anesthesia. Anesthesiology 43: 581-583 (1975).

11. Hamann, R.A. \& Cohen, P.J. Anesthetic management of a patient with epidermolysis bullosa dystrophica. Anesthesiology 34: 389-39l (1971).

12. KELLY, A.J. Epidermolysis bullosa dystrophica anesthetic management. Anesthesiology 35: 659 (1971).

13. LEE, C. \& NAGEL, E.L. Anesthetic management of a patient with recessive epidermolysis dystrophica. Anesthesiology. 43: 122-124(1975).

14. Loverne, S.R. \& Oropollo, A.T. Ketumine anesthesia in dermolytic bullous dermatosis (epidermolysis bullosa). Anesth. Analg. 56: 398-40l (1977)

RÉsumé

L'épidermolyse bulleuse est une maladie héréditaire rare qui peut causer des difficultés anesthésiques importantes secondaires à la malnutrition et l'anémie, les déséquilibres électrolytiques, l'insuffisance rénale et l'amyloidose, la porphyrie associée et le traitement préalable aux stéroides. La fragilité des tissus cutanés et muqueux rend difficile le maintien de l'intégrité des voies aériennes et contrindique l'utilisation de techniques régionales. La canulation veineuse peut s'avérer difficile et la sténose de l'oesophage prédispose à la régurgitation et à l'aspiration.

La conduite de l'anesthésie pour une interposition du colon chez un malade souffrant d'épidermolyse bulleuse avec rétrécissement oesophagien est décrite et les problèmes associées sont discutés. 